\title{
Temporal Correlation between Wall Shear Stress and In-Stent Stenosis after Wingspan Stent in Swine Model
}

\author{
M. Fujimoto, H. Takao, T. Suzuki, Y. Shobayashi, F. Mayor, S. Tateshima, M. Yamamoto, Y. Murayama, and F. Viñuela
}

\begin{abstract}
BACKGROUND AND PURPOSE: A recent randomized clinical trial on intracranial atherosclerosis was discontinued because of the higher frequency of stroke and death in the angioplasty and stent placement group than in the medical treatment group. An in-depth understanding of the relationship between biologic responses and flow dynamics is still required to identify the current limitations of intracranial stent placement.
\end{abstract}

MATERIALS AND METHODS: Five Wingspan stents were deployed in tapered swine ascending pharyngeal arteries. Temporal wall shear stress distributions and in-stent stenosis were evaluated at days $0,7,14$, and 28 after stent placement. The physiologic role of wall shear stress was analyzed regarding its correlation with in-stent stenosis.

RESULTS: In-stent stenosis reached a peak of nearly $40 \%$ at day 14 and decreased mainly at the distal stent segment until day 28 . The wall shear stress demonstrated a characteristic pattern with time on the basis of the in-stent stenosis change. The wall shear stress gradient increased from the proximal to distal segment until day 14. At day 28, the trend was reversed dramatically, decreasing from the proximal to the distal segment. A significant correlation between the in-stent stenosis growth until day 14 and low wall shear stress values just after stent placement was detected. In-stent stenosis regression between days 14 and 28 was also associated with the high wall shear stress values at day 14.

CONCLUSIONS: These data suggest that the physiologic wall shear stress can control the biphasic in-stent stenosis change in tapered arteries.

ABBREVIATIONS: CFD = computational fluid dynamics; IS = in-stent stenosis; ISR = in-stent restenosis; WSS = wall shear stress

T he Wingspan Stent System (Stryker, Kalamazoo, Michigan) is the only endovascular device for symptomatic intracranial atherosclerosis approved by the US Food and Drug Administration. ${ }^{1}$ Although this system has achieved high technical success, the long-term ( $\geq 12$-month) stroke complication rate ranges from $6.4 \%-20.5 \% .^{2-7}$ Furthermore, the only randomized controlled trial, the Stent placement and Aggressive Medical Manage-

Received April 30, 2013; accepted after revision August 26

From the Division of Interventional Neuroradiology (M.F., H.T., Y.S., F.M., S.T., Y.M., F.V.), Department of Radiological Sciences, David Geffen School of Medicine, University of California, Los Angeles, California; Department of Neurosurgery (H.T., T.S., Y.M.), Jikei University School of Medicine, Tokyo, Japan; and Department of Mechanical Engineering (T.S., M.Y.), Graduate School of Engineering, Tokyo University of Science, Tokyo, Japan.

Funding from Division of Interventional Neuroradiology Research funds (F.V.) and research grant from Siemens Japan K.K. (Y.M., H.T.).

Please address correspondence to Motoaki Fujimoto, MD, PhD, Division of Interventional Neuroradiology, Department of Radiological Sciences, David Geffen School of Medicine at UCLA, 10833 Le Conte Ave, Los Angeles, California, 900951721; e-mail: moto.fujimo@gmail.com

http://dx.doi.org/10.3174/ajnr.A3773 ment for Preventing Recurrent stroke in Intracranial Stenosis (SAMMPRIS) trial, showed that aggressive medical treatment was superior to percutaneous transluminal angioplasty and stent placement. In particular, in-stent restenosis (ISR) occurred in approximately $30 \%$ of cases after stent treatments and was a major cause of late-phase stroke. ${ }^{8-10}$ Although revascularization for ISR is relatively safe, $50 \%$ of treated patients experience recurrent restenosis. ${ }^{11}$ An in-depth understanding of ISR after Wingspan stent placement is valuable to identify the current limitations of endovascular treatments of intracranial atherosclerosis and will help to improve this treatment methodology.

Stent placement can prevent arterial recoil and negative remodeling after angioplasty. ${ }^{12}$ ISR mainly involves neointimal hyperplasia characterized by the migration of proliferating smooth muscle cells from the media. The neointimal hyperplasia is proportional to the degree of inflammation, such as that caused by medial damage or penetration of the stent into a lipid core. ${ }^{13,14}$ In addition to the local stent-artery interaction, flow dynamics have been analyzed in their role in the biologic 

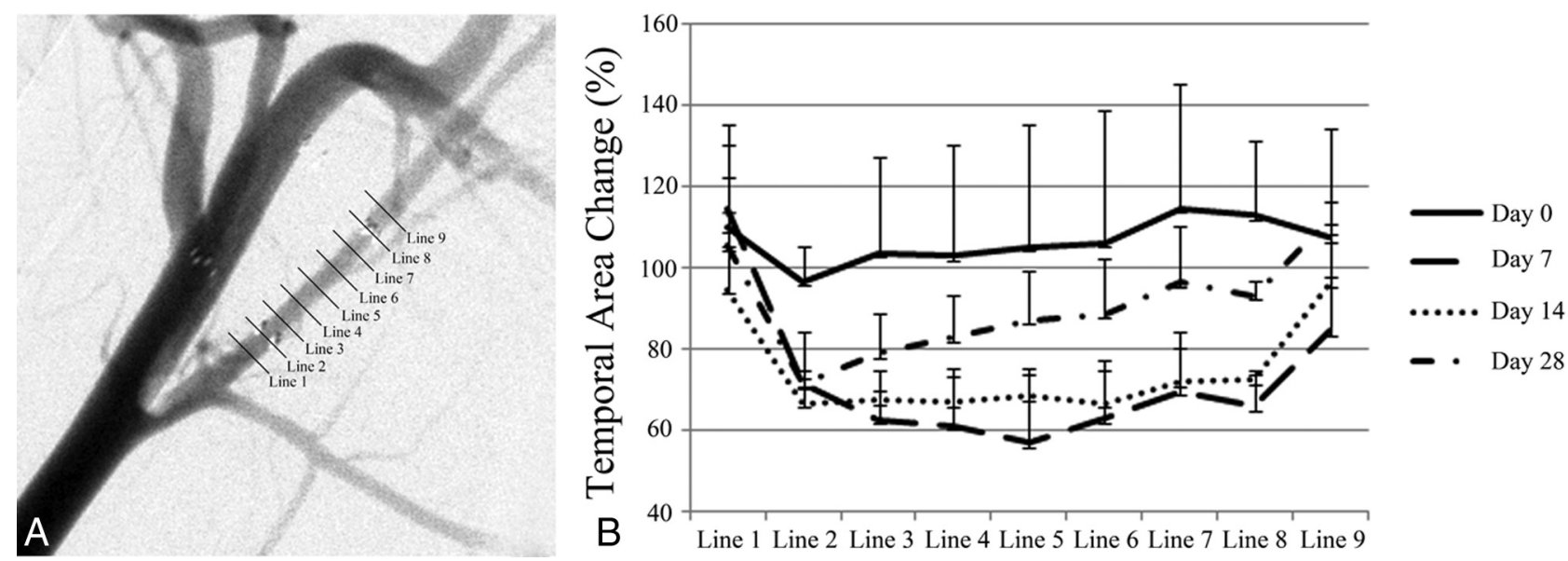

FIG 1. Nine cross-sectional areas at $1.5-\mathrm{mm}$ intervals, including the $1.5 \mathrm{~mm}$ proximal and distal to the stent $(A)$. Temporal area change after Wingspan stent placement, at days $0,7,14$, and 28 , was demonstrated in comparison with the preprocedural area (B).

response after endovascular treatment. In particular, low wall shear stress (WSS) reportedly correlates significantly with neointimal hyperplasia in both clinical and animal models. ${ }^{15-19}$ Optimization of stent design on the basis of WSS has been attempted. ${ }^{20}$

Neointimal hyperplasia is suddenly initiated by arterial wall injury induced by endovascular devices and is stabilized for a limited period. Although drastic structural change can affect subsequent flow dynamics, there are no reports on evaluation of the temporal hemodynamic alterations that occur after stent placement. In our study, we focused the physiologic role of WSS on in-stent stenosis (IS) after Wingspan stent placement in a swine ascending pharyngeal artery.

\section{MATERIALS AND METHODS}

\section{Animal Care}

All animal experiments followed policies set by the Chancellor's Animal Research Committee of the University of California, Los Angeles. A total of 5 ascending pharyngeal arteries in 3 healthy Yorkshire swine (age range, 3-4 months; weight range, 30-40 kg) were included in this study. All endovascular procedures were performed by use of the Allura Xper FD10 System (Philips Healthcare, Best, the Netherlands) as described previously. ${ }^{21}$ In brief, a $6 \mathrm{~F}$ guiding catheter was positioned in the common carotid artery via the right femoral approach. Special interest was paid to the ascending pharyngeal artery, which corresponds to the human internal carotid artery. A segment without large branching and with a proximal diameter of $>2.0$ to $\leq 3.0 \mathrm{~mm}$ was chosen, and the Wingspan stent was delivered. The Wingspan stent is a selfexpandable straight stent with an open-cell design, which is made of nickel-titanium alloy. The stent diameter was followed to the manufacturer's recommendation to exceed the diameter of the referenced arterial diameter by $0-0.5 \mathrm{~mm}$. Three $3.0 \times 9-\mathrm{mm}$ and two $2.5 \times 9$ - $\mathrm{mm}$ stents were used. Three-dimensional rotational angiography was conducted before and after stent placement to construct the arterial models. As for 3D rotational angiography, the $\mathrm{C}$-arm was rotated over $240^{\circ}\left(120^{\circ}\right.$ right anterior oblique to $120^{\circ}$ left anterior oblique) during 4.1 seconds with $\mathrm{x}$-ray acquisition speed at 30 frames per second. During the rota- tional run, a total of 122 isocentric images were generated, resulting in a $256^{3}$ isotropic image volume.

Nine cross-sectional areas at $1.5-\mathrm{mm}$ intervals, including the $1.5 \mathrm{~mm}$ proximal and distal to the stent, were evaluated immediately after stent placement (Fig $1 A$ ). Follow-up angiograms were performed at days 7, 14, and 28 after stent placement. The crosssectional area was measured from the $3 \mathrm{D}$ reconstructed image. IS was defined as a reduction of the sectional area, compared with the area just after stent placement.

\section{Computational Fluid Dynamics Modeling and Analysis Condition}

Steady- and pulsatile laminar-flow analyses were performed as described previously. ${ }^{22}$ The ascending pharyngeal artery was extracted from the reconstructed $3 \mathrm{D}$ data and was converted to a stereolithography-triangulated surface by use of Real Intage (Cybernet Systems, Chiyoda, Tokyo). Surface smoothing was performed with Amira (Visage Imaging, San Diego, California). A volumetric mesh was prepared from the smoothed stereolithography by ICEM CFD 13.0 (ANSYS, Canonsburg, Pennsylvania). The mesh was composed of unstructured grids with mainly tetrahedrons. A mesh-convergence study focusing on the number of mesh elements was performed as reported previously. ${ }^{22}$ The average number of nodes in these models was 1 million. Computational fluid dynamics (CFD) analysis was performed on the volumetric meshes by use of a finite-volume method solver from the general-purpose CFD analysis tool, CFX13.0 (ANSYS). For a typical geometry of the blood vessels, the laminar flow was assumed with a Reynolds number of 250. The Reynolds number was defined as the average velocity and the diameter of an inlet artery. Blood was applied to be a Newtonian fluid with an attenuation of $1100 \mathrm{~kg} / \mathrm{m}^{3}$ and viscous coefficient of $0.0036 \mathrm{~Pa} \times \mathrm{s}$. The inlet condition was $0.0035 \mathrm{~kg} / \mathrm{second}$ as a mass flow rate, which was comparable to the human wave form at a 0 -second point. ${ }^{23}$ Relative pressure on the outlet was set to $0 \mathrm{~Pa}$. As for the time-stepping parameter, we calculated a total of 1.8 seconds as 2 pulsations and 3601 steps in a time-step size of 0.005 second. WSS value was evaluated as the average of WSS for the simulation time course. The Navier-Stokes equations were used to simulate blood flow on 

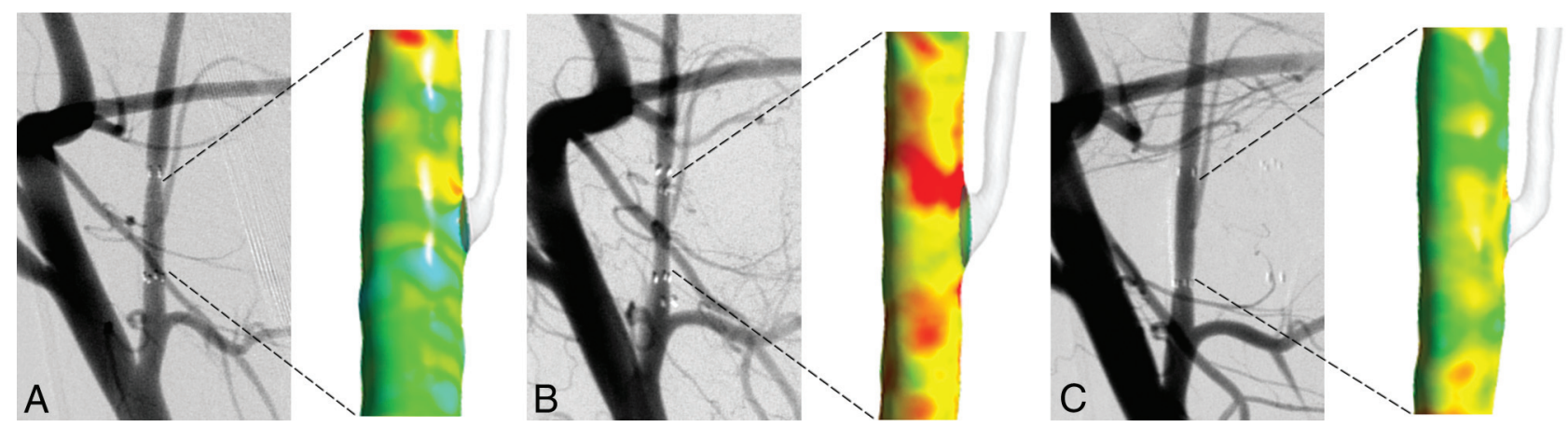

FIG 2. Temporal change of angiography and WSS distributions in a tapered artery. Immediately after stent placement $(A)$ and at day $14(B)$ and day 28 after stent placement (C).

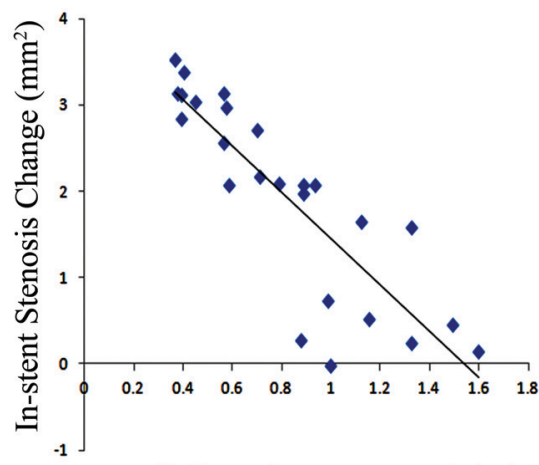

A Wall Shear Stress at Day $0(\mathrm{~Pa})$

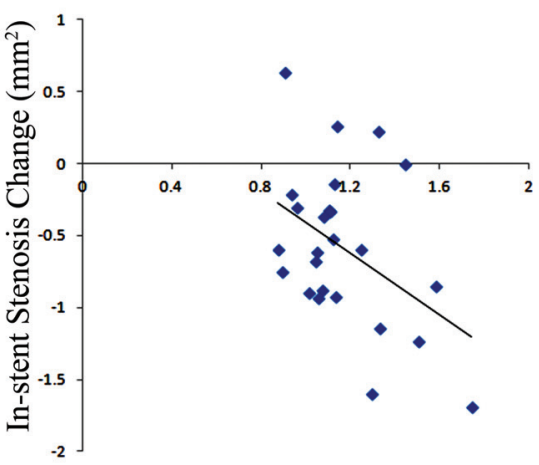

B Wall Shear Stress at Day $14(\mathrm{~Pa})$

FIG 3. Correlation between IS change and the initial WSS for 2 terms, from days $0-14(A)$ and days $14-28(B)$.

the computational mesh. We applied a high-resolution scheme for the advection and a second-order backward Euler scheme for the transient term. The maximal calculation error was $1.7 \%$ between the result of CFX software and the theoretic value by use of the formula in a Poiseuille flow study.

\section{Statistical Analysis}

Statistical comparisons were conducted by use of STATA 12.0 (StataCorp, College Station, Texas). The normality was confirmed by the D'Agostino-Pearson test. The correlation between the area variation and WSS was evaluated by use of the Pearson correlation test. $P$ values of $<.05$ were considered statistically significant.

\section{RESULTS}

\section{Angiographic Change}

The ascending pharyngeal artery showed a tapered shape. The preprocedural luminal ratio of the distal segment (Line 8 ) to the proximal segment (Line 2) was $81.3 \% \pm 7.5 \%$ (Fig $1 A$ ). The temporal area changes at $1.5-\mathrm{mm}$ intervals are shown in Fig $1 B$. Immediately after stent placement, the artery was dilated mainly at the distal stent segment. At days 7-14 after stent placement, IS reached a peak of nearly $40 \%$ for the entire stented artery. At day 28 , the IS decreased by up to $4 \%$ at the distal stent segment.

\section{CFD Simulations}

Stent placement in a tapered artery resulted in marked hemodynamic changes with time (Fig 2). Just after stent placement, the
WSS gradient increased from the proximal to the distal segment according to the tapering lumen. At day 14, WSS values were elevated because of the IS. The distribution pattern of WSS was almost identical to that immediately after stent placement. At day 28, the trend was dramatically reversed and decreased from the proximal to the distal segment.

\section{Correlation between IS Change and WSS}

The correlation between area variations of IS and the initial WSS values was analyzed in the following 2 periods: the growth period from days $0-14$ and the regression period from days $14-28$ (Fig 3). Between days 0 and 14, the IS growth correlated significantly with the low WSS values at day $0\left(R^{2}=0.73 ; P<.001\right)$. A mild correlation between the IS regression between days 14 and 28 and the high WSS values at day 14 was observed $\left(R^{2}=0.19 ; P=.03\right)$.

\section{DISCUSSION}

Shear stress is essential for maintenance of arterial wall function. Disturbed flow, such as that caused by low WSS or oscillatory shear stress, is reportedly associated with atheromatous plaque initiation, progression, and composition. ${ }^{24,25}$ Hemodynamic stress is also responsible for the biologic response after endovascular treatment. From a clinical standpoint, WSS has been shown to correlate inversely with neointimal hyperplasia after coronary stent placement. ${ }^{15,17}$ In addition to WSS, several hemodynamic factors such as the WSS gradients or oscillatory shear stress have been analyzed for their roles in IS in animal models. ${ }^{16,18,19} \mathrm{Al}$ though atherosclerosis and ISR demonstrate many similarities in their process of formation, atherosclerosis is pathophysiologically characterized by progressive lipid accumulation, inflammation, and smooth muscle cell proliferation that continue for many years. ${ }^{12}$ In contrast, neointimal hyperplasia is primarily a selflimited intimal hyperplastic process after arterial wall injury induced by endovascular devices. The physiologic role of WSS in ISR may not necessarily correspond to that in atherosclerotic disease. Temporal IS changes need to be clarified from a flow dynamics standpoint. 
In our study, a characteristic gradient of IS with time was demonstrated after Wingspan stent placement in a tapered swine artery. The IS achieved a peak in whole at day 14 and regressed mainly at the distal stent segment at day 28. As a result, the WSS trend was dramatically reversed to demonstrate a decrease from the proximal to the distal segment at day 28. The WSS correlated significantly with both periods of growth and regression. In particular, the augmented IS in the growth phase correlated strongly with the low WSS. Low WSS was shown to upregulate proinflammatory genes, leading to smooth muscle cell proliferation and migration. ${ }^{26}$ Our results of intracranial self-expandable Wingspan stent placement corresponded with those in previous reports of balloon-expandable stent placement. ${ }^{15-19}$ Furthermore, a mild association between high WSS and the regression of IS between days 14 and 28 was demonstrated. Physiologic increases in WSS from IS may be involved in the regression process. High WSS decreased the inflammation associated with endothelial cell and smooth muscle cell proliferation. ${ }^{27,28}$ Purposefully augmented WSS created by arterial venous shunting or flow-dividing devices has been demonstrated to decrease neointimal hyperplasia. ${ }^{29-31}$ The residual IS at the proximal segment at day 28 may have been caused by both the growth of IS at the proximal segment with low WSS and the regression of IS at the distal segment with high WSS.

In clinical practice, there is often a marked difference in diameter between the proximal and distal segments of an artery, and in such cases of tapering, there is no option but to choose a stent that fits the proximal diameter. An oversized stent at the distal portion of an arterial wall injury can exaggerate the neointimal hyperplasia. ${ }^{19}$ A straight stent with high solid mechanical value can be associated with a higher incidence of restenosis or asymptomatic occlusion than a tapered stent. ${ }^{32,33}$ In addition to solid mechanics, WSS may contribute to both growth and regression of ISR. Further simulation study should evaluate which factors are most responsible for ISR after Wingspan stent placement. A temporal analysis of ISR may be required.

\section{Study Limitations}

Although the WSS change because of the IS can be a reasonable mechanism to explain the biologic response in a tapered artery, our results were limited by the simplified animal model, such as extremely small sample size, lack of any control information, and a straight arterial segment rather than a tortuous segment. Other flow dynamic parameters can be associated with the IS. ${ }^{18}$ Furthermore, temporal IS regulation by WSS may not always be applied for clinical cases with a wide variety of characteristics. Exhaustive analysis with a larger sample size would be desired. Also, our technical limitation of this study was an evaluation method for IS. All area measurements were derived from 3D reconstructed images. The image artifacts by stent markers could make it difficult to evaluate the cross-sectional area at the ends of the stent.

\section{CONCLUSIONS}

We presented the temporal correlation between simulated WSS and IS elicited by Wingspan stent placement in a swine artery. The WSS showed a characteristic pattern in a tapered segment of the artery on the basis of change in IS. The physiologic WSS may play a large role in both the growth and decrement of IS. These insights into time-dependent flow dynamics will be useful for the understanding of biologic responses and for the development of an optimal stent design.

Disclosures: Hiroyuki Takao—RELATED: Grant: Siemens Japan K.K*; UNRELATED: Grants/Grants Pending: FujiFilm, ${ }^{*}$ NTTdocomo. * Yuichi Murayama-UNRELATED: Consultancy: Stryker, ASAHI INTECC, Kakeka; Grants/Grants Pending: Siemens, FujiFilm; Royalties: Stryker. *Money paid to institution.

\section{REFERENCES}

1. Bose A, Hartmann M, Henkes $H$, et al. A novel, self-expanding, nitinol stent in medically refractory intracranial atherosclerotic stenoses: the Wingspan study. Stroke 2007;38:1531-37

2. Chimowitz MI, Lynn MJ, Derdeyn CP, et al. Stenting versus aggressive medical therapy for intracranial arterial stenosis. $N$ Engl J Med 2011;365:993-1003

3. Li J, Zhao ZW, Gao GD, et al. Wingspan stenting with modified predilation for symptomatic middle cerebral artery stenosis. Catheter Cardiovasc Interv 2011;78:286-93

4. Jiang WJ, Yu W, Du B, et al. Outcome of patients with $>/=70 \%$ symptomatic intracranial stenosis after Wingspan stenting. Stroke 2011;42:1971-75

5. Costalat V, Maldonado IL, Vendrell JF, et al. Endovascular treatment of symptomatic intracranial stenosis with the Wingspan stent system and Gateway PTA balloon: a multicenter series of 60 patients with acute and midterm results. J Neurosurg 2011;115:686-93

6. Yu SC, Leung TW, Lee KT, et al. Angioplasty and stenting of atherosclerotic middle cerebral arteries with Wingspan: evaluation of clinical outcome, restenosis, and procedure outcome. AJNR Am J Neuroradiol 2011;32:753-58

7. Fiorella DJ, Turk AS, Levy EI, et al. U.S. Wingspan Registry: 12month follow-up results. Stroke 2011;42:1976-81

8. Levy EI, Turk AS, Albuquerque FC, et al. Wingspan in-stent restenosis and thrombosis: incidence, clinical presentation, and management. Neurosurgery 2007;61:644-50; discussion 650-51

9. Albuquerque FC, Levy EI, Turk AS, et al. Angiographic patterns of Wingspan in-stent restenosis. Neurosurgery 2008;63:23-27; discussion 27-28

10. Turk AS, Levy EI, Albuquerque FC, et al. Influence of patient age and stenosis location on Wingspan in-stent restenosis. AJNR Am J Neuroradiol 2008;29:23-27

11. Fiorella DJ, Levy EI, Turk AS, et al. Target lesion revascularization after Wingspan: assessment of safety and durability. Stroke 2009;40:106-10

12. Kibos A, Campeanu A, Tintoiu I. Pathophysiology of coronary artery in-stent restenosis. Acute Card Care 2007;9:111-19

13. Farb A, Weber DK, Kolodgie FD, et al. Morphological predictors of restenosis after coronary stenting in humans. Circulation 2002;105:2974-80

14. Welt FG, Rogers C. Inflammation and restenosis in the stent era. Arterioscler Thromb Vasc Biol 2002;22:1769-76

15. Wentzel JJ, Krams R, Schuurbiers JC, et al. Relationship between neointimal thickness and shear stress after Wallstent implantation in human coronary arteries. Circulation 2001;103:1740-45

16. LaDisa JF Jr, Olson LE, Molthen RC, et al. Alterations in wall shear stress predict sites of neointimal hyperplasia after stent implantation in rabbit iliac arteries. Am J Physiol Heart Circ Physiol 2005;288:H2465-75

17. Papafaklis MI, Bourantas CV, Theodorakis PE, et al. The effect of shear stress on neointimal response following sirolimus- and paclitaxel-eluting stent implantation compared with bare-metal stents in humans. JACC Cardiovasc Interv 2010;3:1181-89

18. Morlacchi S, Keller B, Arcangeli P, et al. Hemodynamics and in-stent restenosis: micro-CT images, histology, and computer simulations. Ann Biomed Eng 2011;39:2615-26

19. Chen HY, Sinha AK, Choy JS, et al. Mis-sizing of stent promotes 
intimal hyperplasia: impact of endothelial shear and intramural stress. Am J Physiol Heart Circ Physiol 2011;301:H2254-63

20. Gundert TJ, Marsden AL, Yang W, et al. Optimization of cardiovascular stent design using computational fluid dynamics. J Biomech Eng 2012;134:011002

21. Fujimoto M, Shobayashi Y, Tateshima S, et al. Biomechanical responses after Wingspan stent deployment in swine ascending pharyngeal artery. Neurol Res 2013;35:90-94

22. Takao H, Murayama Y, Otsuka S, et al. Hemodynamic differences between unruptured and ruptured intracranial aneurysms during observation. Stroke 2012;43:1436-39

23. Ford MD, Alperin N, Lee SH, et al. Characterization of volumetric flow rate waveforms in the normal internal carotid and vertebral arteries. Physiol Meas 2005;26:477-88

24. Samady H, Eshtehardi P, McDaniel MC, et al. Coronary artery wall shear stress is associated with progression and transformation of atherosclerotic plaque and arterial remodeling in patients with coronary artery disease. Circulation 2011;124:779-88

25. Eshtehardi P, McDaniel MC, Suo J, et al. Association of coronary wall shear stress with atherosclerotic plaque burden, composition, and distribution in patients with coronary artery disease. $J \mathrm{Am}$ Heart Assoc 2012;1:e02543

26. Chatzizisis YS, Coskun AU, Jonas M, et al. Role of endothelial shear stress in the natural history of coronary atherosclerosis and vascu- lar remodeling: molecular, cellular, and vascular behavior. $J \mathrm{Am}$ Coll Cardiol 2007;49:2379-93

27. Ueba H, Kawakami M, Yaginuma T. Shear stress as an inhibitor of vascular smooth muscle cell proliferation. Role of transforming growth factor-beta 1 and tissue-type plasminogen activator. Arterioscler Thromb Vasc Biol 1997;17:1512-16

28. Sheikh S, Rainger GE, Gale Z, et al. Exposure to fluid shear stress modulates the ability of endothelial cells to recruit neutrophils in response to tumor necrosis factor-alpha: a basis for local variations in vascular sensitivity to inflammation. Blood 2003;102:2828-34

29. Carlier SG, van Damme LC, Blommerde CP, et al. Augmentation of wall shear stress inhibits neointimal hyperplasia after stent implantation: inhibition through reduction of inflammation? Circulation 2003;107:2741-46

30. Wentzel JJ, Gijsen FJ, Stergiopulos N, et al. Shear stress, vascular remodeling and neointimal formation. J Biomech 2003;36:681-88

31. Mattsson EJ, Kohler TR, Vergel SM, et al. Increased blood flow induces regression of intimal hyperplasia. Arterioscler Thromb Vasc Biol 1997;17:2245-49

32. Brown KE, Usman A, Kibbe MR, et al. Carotid stenting using tapered and nontapered stents: associated neurological complications and restenosis rates. Ann Vasc Surg 2009;23:439-45

33. Auricchio F, Conti M, De Beule M, et al. Carotid artery stenting simulation: from patient-specific images to finite element analysis. Med Eng Phys 2011;33:281-89 